\title{
Formulation and Nutritional Assessment of Ready to Serve Supplementary Maternal Food
}

\author{
Ruth Bekele \\ Department of Food Science and Nutrition, Ethiopian Institute of Agricultural Research, Addis Ababa, Ethiopia \\ Email address: \\ rutinajc@gmail.com

\section{To cite this article:} \\ Ruth Bekele. Formulation and Nutritional Assessment of Ready to Serve Supplementary Maternal Food. International Journal of Food \\ Science and Biotechnology. Vol. 6, No. 2, 2021, pp. 53-58. doi: 10.11648/j.ijfsb.20210602.15
}

Received: April 30, 2021; Accepted: June 10, 2021; Published: June 21, 2021

\begin{abstract}
Poor nutrition during pregnancy and lactation periods put mothers and their growing children at a greater risk of disease, mental disorders, and death. Maternal nutrition during pregnancy influences the growth of the fetus and contributes to the development of a healthy baby. Consumption of a nutritionally balanced supplementary maternal food to meet the additional nutritional demand during pregnancy and lactation is a sustainable option for tackling the co-existence of undernutrition in pregnant women and children. The aim of this study was to formulate nutrient rich ready to serve supplementary maternal food from barely, teff, bean, sesame seeds, pumpkin seed, and groundnut. The proximate composition of formulations was determined using official method of AOAC. The results showed that treatment formulation $\mathrm{SFF}_{1}$ which is Barley $=40 \%$; Teff $=15 \%$; Bean $=20 \%$; Sesame $=5 \%$; Pumpkin Seed $=15 \%$ and Groundnut $=5 \%$ had the most desirable nutritional benefits among the formulated supplementary maternal food. The appearance and taste of the prepared supplementary drink was acceptable and was found to be nutritious to meet the required additional nutrition for pregnant and lactating mothers. It is recommended to drink $500 \mathrm{ml}$ of the supplementary drink per day to meet the daily Dietary Reference Intake (DRI) in addition to the ordinary meals.
\end{abstract}

Keywords: Bioavailability, Energy, Minerals, Protein, Supplementary Food

\section{Introduction}

Adequate nutrient intake during the various stages of pregnancy and lactation is important for the proper fetal growth and production of breast milk. Nutrient needs during these periods are relatively higher compared to women who are not pregnant or lactating [1]. Maternal malnutrition is responsible to a great extent for millions of childhood deaths and incidences of diseases every year in lower-income countries [2]. The damage caused by poor nutrition in the womb or in the first years of life will be a burden that the infant /child must bear for the rest of his/her life. Maternal nutrition at pregnancy influences the growth and potential development of the fetus and contributes to the maturity of a healthy baby [3].

The extent and consequences of malnutrition among pregnant women is highly prevalent in developing countries particularly in Sub Saharan Africa, resulting in substantial increases in disease burden and mortality [4]. This may be due to poverty, low dietary intake, inequitable distribution of food within the household, food insecurity and dietary taboos $[2,5]$.
According to Ethiopian Demographic Health Survey in [6] 22\% of women were malnourished and $24 \%$ were anaemic. Anaemia among pregnant women is a severe public health problem in Ethiopia with an overall prevalence of $62.7 \%$. In addition, $24 \%$ of children under the age of 5 are underweight, $38 \%$ of children are stunted and $10 \%$ are wasted.

The main nutritional issues impacting pregnant women are protein and energy malnutrition and deficiencies of micronutrients, such as iron, folate, calcium, vitamin D and vitamin A [2, 5]. Consumption of locally available nutrient-dense foods is being emphasized as sustainable option for tackling undernutrition [7]. Therefore, formulation of supplementary maternal food for the additional nutrient need is important for a healthy pregnancy.

The objective of this study is to develop nutrient rich ready to serve supplementary maternal food to meet the additional nutrient requirement of a pregnant women from the second trimester and lactating mothers. The nutritional composition, antinutritional factor, bioavailability, and sensory evaluation of the formulated ready to serve supplementary food were determined. 


\section{Materials and Methods}

The study was conducted in the experimental kitchen of Food Science and Nutrition Research Directorate at Ethiopian Institute of Agricultural Research in 2018 and 2019, Addis Ababa. The ingredients used for the formulation of ready to serve maternal supplementary food were barley, teff, bean, sesame seed, pumpkin seed, and groundnut. These ingredients were selected based on their nutritional benefits and organoleptic property.

\subsection{Preparation of Ingredients in Ready to Serve Supplementary Maternal Food}

Ingredients for ready to serve supplementary maternal food were prepared as follows.

Barley: A local variety of barley HB1307 was obtained from Holeta Agricultural Research Centre. The grains were cleaned, soaked overnight in water and the bran layer were removed by pounding. After dehulling, it was dried for 8 hours and roasted until its uniformly brown in colour and stored at room temperature until needed [8].

Bean: A local variety of biofortified bean, (GLP II) was obtained from Melkassa Agricultural Research Centre. It was cleaned, washed, soaked overnight in water, drained and steamed for about 10 minutes. The steamed beans were cooked for about 30 minutes to reduce anti-nutritional factors. Beans were cooled to room temperature and the skin was removed by hand. The beans were then oven dried and roasted for about $5 \mathrm{~min}$ to improve the flavour [9]. The dried beans were stored at room temperature until needed.

Teff: A local variety of teff, Kora (DZ-Cr-438), was obtained from Debre-zeit Agricultural Research Centre. It was cleaned and milled into flour. The flour was lightly toasted on a pan to remove the raw taste and stored at room temperature until needed.

Pumpkin seed: Pumpkin seeds purchased from local market were cleaned and lightly roasted and stored at room temperature until needed.

Sesame seed: Sesame seeds purchased from the local market was cleaned, soaked overnight in water, dehulled by hand rubbing, oven dried and lightly roasted and stored at room temperature until needed.

Preparation of groundnut: A local variety of groundnut (Sedi) was obtained from Werer Agricultural Research Centre. Then it was de-skinned, sorted, lightly roasted, dehulled, and stored at room temperature until needed.

Mixing of the ingredients: All ingredients were prepared separately and blended according to the proportions of different treatment formulations. The ingredients for the various treatments were milled together to give separate formulations. Table 1 presents different proportions of weight expressed as percentages for each ingredient's formulations of five treatments.

\subsection{Formulations of Ready to Serve Supplementary Maternal Food}

The treatments consisted of fixed proportions of barley, teff, bean with various proportions of sesame, pumpkin, and groundnut to formulate the ready to serve supplementary maternal food (RTSSMF). The treatments were blended to meet the nutrient requirements of pregnant women after their first trimester and lactating mothers.

Table 1. Formulation of ready to serve supplementary maternal food treatments (\%).

\begin{tabular}{|c|c|c|c|c|c|c|}
\hline Treatments & Barely & Teff & Bean & Sesame & Pumpkin seed & Groundnut \\
\hline $\mathrm{SFF}_{1}$ & 40 & 15 & 20 & 5 & 15 & 5 \\
\hline $\mathrm{SFF}_{2}$ & 40 & 15 & 20 & 15 & 5 & 5 \\
\hline $\mathrm{SFF}_{3}$ & 40 & 15 & 20 & 15 & 0 & 10 \\
\hline $\mathrm{SFF}_{4}$ & 40 & 15 & 20 & 0 & 15 & 10 \\
\hline $\mathrm{SFF}_{5}$ & 40 & 15 & 20 & 10 & 10 & 5 \\
\hline
\end{tabular}

$\mathrm{SFF}=$ supplementary food formulation and the subscript numbers 1, 2, 3, 4, 5 represents treatment number

\subsection{Nutritional Composition Analysis}

\subsubsection{Proximate Composition}

Proximate composition of the formulation treatments was determined using official method of AOAC [10]. Moisture content was determined by drying the samples in air convection oven at $130^{\circ} \mathrm{C}$ for one hour. Total ash was determined by incinerating $2 \mathrm{~g}$ of sample in a furnace at $550^{\circ} \mathrm{C}$ until the colour changed to grey/white. Crude fat was determined by solvent extraction using Soxtec extraction system (Soxtec 8000, FOSS). Nitrogen content of samples was determined according to Kjeldahl using block digestion and steam distillation with Tecator Kjeltec Systems (Kjeltec 8400 , FOSS). Crude protein was estimated by multiplying N content by 6.25 , Crude fibre was determined according to method according to official method of AOAC [11], number 978. Total carbohydrate was determined using difference method by subtracting measured protein, fat, ash, and moisture from 100 [12]. The gross energy value was estimated (in $\mathrm{kcal} / \mathrm{g}$ ) by multiplying the percentages of crude protein, crude lipid and carbohydrate using the Atwater's conversion factors; $16.7 \mathrm{~kJ} / \mathrm{g}$ (4 kcal/g) for protein, $37.4 \mathrm{~kJ} / \mathrm{g}$ $(9 \mathrm{kcal} / \mathrm{g})$ for fat and $16.7 \mathrm{~kJ} / \mathrm{g}(4 \mathrm{kcal} / \mathrm{g})$ for carbohydrates and expressed in calories [13].

\subsubsection{Determination of Mineral and Phytate}

Mineral content was determined using graphite furnace atomic absorption instrument according to AOAC [11]. Phytate was determined using spectrophotometer at $500 \mathrm{~nm}$ as in [14].

\subsubsection{Bioavailability}

Mineral bioavailability was estimated using molar ration of phytate to mineral. The mole of phytate and minerals was 
determined by dividing the weight of phytate and minerals with its atomic weight (phytate: $660 \mathrm{~g} / \mathrm{mol}$; Fe: $56 \mathrm{~g} / \mathrm{mol}$; $\mathrm{Zn}$ : $65 \mathrm{~g} / \mathrm{mol}$; Ca: $40 \mathrm{~g} / \mathrm{mol}$ ). The molar ratio between phytate and mineral was obtained after dividing the mole of phytate with the mole of minerals.

\subsection{Preparation of Supplementary Maternal Food}

The RTSSMF treatments were prepared by mixing $50 \mathrm{~g}$ powder with $110 \mathrm{ml}$ of water (room temperature), 2 tablespoon sugar and a pinch of salt.

\subsection{Sensory Evaluation}

Sensory evaluation was done by 21 pregnant women and mothers randomly selected among the staff at EIAR. A five-point hedonic scale was used for sensory evaluations where 5 was 'like very much' and 1 'dislike' for each of the sensory attributes (appearance, flavour, colour, taste, and overall acceptability).

\subsection{Statistical Analysis}

Analysis of Variance (ANOVA) was used to test treatment differences. Data was analysed using the General Linear Model procedure of SAS software. Duncan multiple comparisons were deployed to separate treatment means. Differences among means with $\mathrm{p}<0.05$ was taken as representing statistically significant differences.

\section{Result and Discussion}

\subsection{Nutritional Composition of Supplementary Maternal Food}

The nutritional composition ( $\mathrm{g} / 100 \mathrm{~g}$ dry weight) of formulated RTSSMF treatments is presented in Table 2. There was significant $(p<0.05)$ difference between treatments.

There were significant differences in the moisture content 4.48 to $5.64 \mathrm{~g} / 100 \mathrm{~g}$ of the formulated treatments. Powdered foods with lower content of moisture $(<10 \%)$ are suitable for extended shelf life. Low moisture contents of formulations are also convenient for packaging and transport of products [15].

The fat content of formulated treatments ranged from 12.32 to $14.90 \mathrm{~g} / 100 \mathrm{~g}$ and there was significant difference. Lipids are essential for formation of cell membranes hormones and necessary for proper eye and brain development. The daily total fat intake during pregnancy and lactation recommendations are related to energy requirements and fat should supply $20 \%$ to $35 \%$ of a woman's total energy [16]. All the formulated treatments give $27.1-32.4 \%$ of energy from fat, which could meet required fat content for total energy needs during pregnancy and lactation. The fat content in $\mathrm{SFF}_{3}$ was found to be higher among the treatments which may be the result of higher proportion of sesame and groundnut in the formulation.

Table 2. Proximate composition of formulated supplementary maternal food $(\mathrm{g} / 100 \mathrm{~g})$.

\begin{tabular}{|c|c|c|c|c|c|c|c|}
\hline Treatments & Moisture & Fat & Protein & Fiber & Ash & Carbohydrate & Energy (Kcal/100g) \\
\hline $\mathrm{SFF}_{1}$ & $5.64^{\mathrm{a}}$ & $12.39^{\mathrm{d}}$ & $16.33^{\mathrm{a}}$ & $6.56^{\mathrm{c}}$ & $2.71^{\mathrm{ab}}$ & $56.38^{\mathrm{bc}}$ & $411.34^{\mathrm{c}}$ \\
\hline $\mathrm{SFF}_{2}$ & $4.48^{\mathrm{c}}$ & $14.70^{\mathrm{b}}$ & $15.38^{\mathrm{d}}$ & $6.58^{\mathrm{c}}$ & $2.77^{\mathrm{a}}$ & $56.10^{\mathrm{c}}$ & $418.15^{\mathrm{a}}$ \\
\hline $\mathrm{SFF}_{3}$ & $4.41^{\mathrm{d}}$ & $14.90^{\mathrm{a}}$ & $15.38^{\mathrm{d}}$ & $8.21^{\mathrm{a}}$ & $2.68^{\mathrm{ab}}$ & $54.45^{\mathrm{d}}$ & $413.38^{b}$ \\
\hline $\mathrm{SFF}_{5}$ & $4.49^{c}$ & $13.63^{\mathrm{c}}$ & $15.73^{\mathrm{c}}$ & $5.30^{\mathrm{d}}$ & $2.63^{\mathrm{ab}}$ & $58.28^{\mathrm{a}}$ & $418.69^{\mathrm{a}}$ \\
\hline $\mathrm{CV}$ & 0.59 & 0.42 & 0.35 & 2.26 & 2.86 & 0.41 & 0.15 \\
\hline Mean & 4.72 & 13.59 & 15.87 & 6.77 & 2.67 & 56.39 & 411.34 \\
\hline
\end{tabular}

Means followed by the same letter within a column are not significantly different $(p>0.05)$

$\mathrm{SFF}_{1}=40 \%$ Barley $+15 \%$ Teff $+20 \%$ Bean $+5 \%$ Sesame $+15 \%$ PumpkinSeed $+5 \%$ groundnut,

$\mathrm{SFF}_{2}=40 \%$ Barley $+15 \%$ Teff $+20 \%$ Beans $+15 \%$ Sesame $+5 \%$ Pumpkinseed $+5 \%$ groundnut, $\quad \mathrm{SFF}_{3}=40 \% \mathrm{Barley}+15 \% \mathrm{Teff}+20 \% \mathrm{Bean}+15 \% \mathrm{Sesame}+10 \%$ groundnut, $\mathrm{SFF}_{4}=40 \%$ Barley $+15 \%$ Teff $+20 \%$ Bean $+15 \%$ PumpkinSeed $+10 \%$ groundnut and $\mathrm{SFF}_{5}=40 \%$ Barley $+15 \%$ Teff $+20 \%$ Bean $+10 \%$ Sesame $+10 \%$ Pumpkin Seed + $5 \%$ groundnut; CV coefficient of variation

The WHO [17] recommends that pregnant women should consume 9 and $31 \mathrm{~g}$ of additional protein daily during the second and third trimesters, respectively. The protein content of formulated treatments was in the range of $15.38-16.54$ $\mathrm{g} / 100 \mathrm{~g}$ and has significant difference. Protein is a constituent of all cells and a component of enzymes, membranes, transport carriers, and many hormones. The suggested additional daily protein for lactating women during the first and second 6 months is 19 and $12.5 \mathrm{~g}$ respectively. $\mathrm{SFF}_{1}$ and $\mathrm{SFF}_{2}$ showed a higher content of protein which may be a caused by higher proportion of pumpkin seed and groundnut. All the formulated treatments could meet more than $50 \%$ of the additional daily required protein for both pregnant and lactating women.

Fiber content of formulated treatments ranged between $5.30-8.21 \mathrm{~g} / 100 \mathrm{~g}$ and there were significant differences among treatments. Fiber is non-digestible carbohydrate and found as lignin in plant derived foods. Benefits of dietary fibers include feelings of fullness and improved bowel movement, which could help reduce the chances for hemorrhoids during pregnancy. The Adequate Intake (AI) for fiber during pregnancy and lactation is 14 grams per 1,000 calories [18]. Thus, all the formulated treatments could meet more than $100 \%$ of the required fiber for both pregnant and lactating women at the given energy value of the RTSSMF.

The Dietary Reference Intake (DRI) of carbohydrate for a pregnant woman is 45 grams above the non-pregnancy state and 80 grams for lactating woman to compensate for the carbohydrate secreted in breast milk [18]. The carbohydrate content of the formulated treatments ranged between 54.45 to $58.28 \mathrm{~g} / 100 \mathrm{~g}$ and there was a significant difference between the treatments. The formulated supplementary food provides 
more than $100 \%$ of the additional carbohydrate required for pregnant women and $67 \%$ of nursing mothers.

The energy value of formulated treatments the showed significant difference and ranged from $411.3-418.6 \mathrm{kcal} / 100 \mathrm{~g}$. The suggested calorie increases for women who conceive at a normal body weight range is 340 calories a day in the second trimester and to consume 330 additional calories per day for the first six months after delivery [18]. The formulated supplementary food provides more than $124 \%$ of the additional energy required for both pregnant women and nursing mothers.

The amount of ash for all formulated supplementary maternal foods has significant differences and were found in the range of $2.38 \%-2.66 \%$. Ash contents the shows presence of mineral in the treatments.

\subsection{Mineral Composition and Phytate of Supplementary Maternal Food}

The amount of phytate, iron, zinc, and calcium of formulated treatments $(\mathrm{mg} / 100 \mathrm{~g})$ were summarized in Table 3. All the formulated treatments showed significant differences at $(\mathrm{p}<0.05)$.

The phytate in the formulated treatments was significantly different and ranged between 178 - $595.24 \mathrm{mg} / 100$. The higher amount of phytate was found in treatment $\mathrm{SFF}_{5}$ and the lowest in treatment $\mathrm{SFF}_{3}$. The lowest and the highest amount of phytate may be due to different proportion of sesame and pumpkin seeds.

Table 3. Amount of phytate and minerals in the supplementary maternal food formulations ( $\mathrm{mg} / 100 \mathrm{~g})$.

\begin{tabular}{lllll}
\hline Treatment & Phytate & Ca & Fe & Zn \\
\hline $\mathrm{SFF}_{1}$ & $218.96^{\mathrm{b}}$ & $102.10^{\mathrm{b}}$ & $23.02^{\mathrm{a}}$ & $3.53^{\mathrm{ab}}$ \\
$\mathrm{SFF}_{2}$ & $218.96^{\mathrm{c}}$ & $103.20^{\mathrm{b}}$ & $19.50^{\mathrm{c}}$ & $3.62^{\mathrm{a}}$ \\
$\mathrm{SFF}_{3}$ & $178.47^{\mathrm{d}}$ & $129.9^{\mathrm{a}}$ & $21.13^{\mathrm{b}}$ & $3.25^{\mathrm{c}}$ \\
$\mathrm{SFF}_{4}$ & $219.40^{\mathrm{b}}$ & $55.8^{\mathrm{d}}$ & $21.13^{\mathrm{b}}$ & $3.15^{\mathrm{c}}$ \\
$\mathrm{SFF}_{5}$ & $595.24^{\mathrm{a}}$ & $72.45^{\mathrm{c}}$ & $21.83^{\mathrm{b}}$ & $3.44^{\mathrm{b}}$ \\
$\mathrm{CV}$ & 1.55 & 1.95 & 2.06 & 2.48 \\
Mean & 283.84 & 92.69 & 21.35 & 3.40 \\
\hline
\end{tabular}

Means followed by the same letter within a column are not significantly

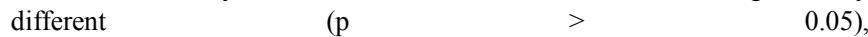
$\mathrm{SFF}_{1}=40 \%$ Barley $+15 \%$ Teff $+20 \%$ Bean $+5 \%$ Sesame $+15 \%$ PumpkinSeed $+5 \%$ g roundnut,

$\mathrm{SFF}_{2}=40 \%$ Barley $+15 \%$ Teff $+20 \%$ Beans $+15 \%$ Sesame $+5 \%$ Pumpkinseed $+5 \%$ groundnut,

$\mathrm{SFF}_{3}=40 \%$ Barley $+15 \%$ Teff $+20 \%$ Bean $+15 \%$ Sesame $+10 \%$ groundnut, $\mathrm{SFF}_{4}=40 \%$ Barley $+15 \%$ Teff $+20 \%$ Bean $+15 \%$ PumpkinSeed $+10 \%$ groundnut and $\mathrm{SFF}_{5}=40 \%$ Barley $+15 \%$ Teff $+20 \%$ Bean $+10 \%$ sesame $+10 \%$ Pumpkin Seed $+5 \%$ groundnut; $\mathrm{CV}$ coefficient of variation

The dietary reference intake (DRI) of iron during pregnancy is $27 \mathrm{mg} /$ day and $9 \mathrm{mg} /$ day for lactating women [19]. The amount of iron in this study was significantly different and ranged between $19.5-23.03 \mathrm{mg} / 100 \mathrm{~g}$. Iron is vital to the production of hemoglobin, and energy production, fetal immunity, and development of the central nervous system. The suggested additional daily iron requirement for pregnant woman is $9 \mathrm{mg}$ and all the formulated treatments could meet $211 \%$ of the additional and $70-85 \%$ of the total daily required amount of iron for both pregnant and lactating women.

Zinc was significantly different at $(p<0.05)$ in the formulated treatments and ranged between $3.15-3.6 \mathrm{mg} / 100 \mathrm{~g}$. The primary function of zinc is to promote cell reproduction and tissue growth and repair, it is essential for growth and development, as well as reproduction and immunity [19]. Zinc plays a critical role in embryogenesis and fetal growth, as well as being secreted in breast milk, the body's need for zinc is greater during pregnancy and lactation [20]. The recommended additional daily zinc requirement for pregnant and lactating woman is 3 and $4 \mathrm{mg}$ respectively [16]. All the formulated treatments provide more than $100 \%$ and $75 \%$ of the additional required amount of zinc for pregnant and lactating mothers respectively, and $25 \%$ of the total amount of zinc required per day.

The recommended intake for calcium established by $\mathrm{FAO} / \mathrm{WHO}$ [21] for pregnant and lactating women is 1000 $\mathrm{mg}$ /day but increases to $1200 \mathrm{mg} /$ day during the last trimester of pregnancy. The amount of calcium was significantly different at $(p<0.05)$ and ranged between 77.92 to $109.6 \mathrm{mg} / 100 \mathrm{~g}$. In this study all the formulated foods provide about $10 \%$ of the daily required amount of calcium for both pregnant and lactating mothers. Calcium has structural and metabolic functions. The skeleton and teeth serve as reservoirs for about $99 \%$ of the body's calcium; it plays a role in vascular contraction and vasodilation, muscle contraction, and nerve transmission [22].

\subsection{Bioavailability of Minerals}

Table 4. Bioavailability of the minerals in supplementary maternal food (mg/lo0g).

\begin{tabular}{llll}
\hline Treatments & Phytate: Ca & Phytate: Fe & Phytate: Zn \\
\hline Critical Values & $>0.24$ & $>1$ & $>15$ \\
$\mathrm{SFF}_{1}$ & $0.063^{\mathrm{e}}$ & $0.807^{\mathrm{c}}$ & $6.126^{\mathrm{c}}$ \\
$\mathrm{SFF}_{2}$ & $0.112^{\mathrm{c}}$ & $0.90^{\mathrm{b}}$ & $5.647^{\mathrm{d}}$ \\
$\mathrm{SFF}_{3}$ & $0.149^{\mathrm{b}}$ & $0.717^{\mathrm{d}}$ & $5.417^{\mathrm{d}}$ \\
$\mathrm{SFF}_{4}$ & $0.113^{\mathrm{c}}$ & $0.875^{\mathrm{b}}$ & $6.858^{\mathrm{b}}$ \\
$\mathrm{SFF}_{5}$ & $0.149^{\mathrm{b}}$ & $2.314^{\mathrm{a}}$ & $17.044^{\mathrm{a}}$ \\
$\mathrm{CV}$ & 0.925 & 2.384 & 2.969 \\
Mean & 0.130 & 1.123 & 8.218 \\
\hline
\end{tabular}

Means followed by the same letter within a column are not significantly

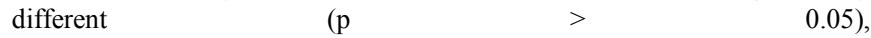
$\mathrm{SFF}_{1}=40 \%$ Barley $+15 \%$ Teff $+20 \%$ Bean $+5 \%$ Sesame $+15 \%$ PumpkinSeed $+5 \% \mathrm{~g}$ roundnut,

$\mathrm{SFF}_{2}=40 \%$ Barley $+15 \%$ Teff $+20 \%$ Beans $+15 \%$ Sesame $+5 \%$ Pumpkinseed $+5 \%$ groundnut,

$\mathrm{SFF}_{3}=40 \%$ Barley $+15 \%$ Teff $+20 \%$ Bean $+15 \%$ Sesame $+10 \%$ groundnut, $\mathrm{SFF}_{4}=40 \%$ Barley $+15 \%$ Teff $+20 \%$ Bean $+15 \%$ PumpkinSeed $+10 \%$ groundnut and $\mathrm{SFF}_{5}=40 \%$ Barley $+15 \%$ Teff $+20 \%$ Bean $+10 \%$ sesame $+10 \%$ Pumpkin Seed $+5 \%$ groundnut; $\mathrm{CV}$ coefficient of variation

In developing countries, bioavailability of micronutrients is a main concern due to plant based and unvaried diets. Micronutrients such as calcium, iron and zinc are very important in maternal nutrition both for the mother and the fetus. Critical values for the bioavailability of minerals are Phytate: $\mathrm{Ca}>0.24$, Phytate: $\mathrm{Fe}>1$ and Phytate: $\mathrm{Zn}>15$. The mineral is poorly available if the concentration of phytate is greater than the critical numbers. As shown in Table 4, there is 
a significance difference in the bioavailability of minerals among the treatments at $(\mathrm{p}<0.05)$.

Calcium is bioavailable in all formulated treatments and the calcium in treatment $\mathrm{SFF}_{1}$ is found to be most available. Iron is bioavailable in all treatments except in $\mathrm{SFF}_{5}$, which is found to be poorly available. The critical value for iron is molar ratio of phytate/Iron more than 1 is being considered as poorly available. Zinc is bioavailable in all formulated treatments except in treatment $\mathrm{SFF}_{5}$.

\subsection{Sensory Evaluation}

Table 5 summarizes the organoleptic property of the formulated RTSSMF treatments. As it is shown in the table there is no significance difference in all sensory parameters at $(p<0.05)$. All the formulated supplementary maternal foods were acceptable by pregnant women and lactating mothers.

Table 5. Sensory analysis of the supplementary maternal food (mg/100g).

\begin{tabular}{|c|c|c|c|c|c|}
\hline Treatment & Appearance & Flavour & Colour & Taste & Overall acceptability \\
\hline $\mathrm{SFF}_{1}$ & $4.11^{\mathrm{a}}$ & $3.72^{\mathrm{ab}}$ & $4.28^{\mathrm{a}}$ & $3.72^{\mathrm{a}}$ & $3.94^{\mathrm{a}}$ \\
\hline $\mathrm{SFF}_{2}$ & $4.05^{\mathrm{a}}$ & $3.67^{\mathrm{ab}}$ & $4.22^{\mathrm{a}}$ & $4.00^{\mathrm{a}}$ & $3.88^{\mathrm{a}}$ \\
\hline $\mathrm{SFF}_{3}$ & $4.16^{\mathrm{a}}$ & $3.6^{\mathrm{b}}$ & $4.11^{\mathrm{a}}$ & $4.05^{\mathrm{a}}$ & $4.00^{\mathrm{a}}$ \\
\hline $\mathrm{SFF}_{5}$ & $4.38^{\mathrm{a}}$ & $4.00^{\mathrm{a}}$ & $4.33^{\mathrm{a}}$ & $3.83^{\mathrm{a}}$ & $3.94^{\mathrm{a}}$ \\
\hline $\mathrm{CV}$ & 4.18 & 3.76 & 4.23 & 3.89 & 3.94 \\
\hline Mean & 12.18 & 12.59 & 11.91 & 13.54 & 14.19 \\
\hline
\end{tabular}

$\mathrm{SFF}_{1}=40 \%$ Barley $+15 \%$ Teff $+20 \%$ Bean $+5 \%$ Sesame $+15 \%$ PumpkinSeed $+5 \%$ groundnut,

$\mathrm{SFF}_{2}=40 \%$ Barley $+15 \%$ Teff $+20 \%$ Beans $+15 \%$ Sesame $+5 \%$ Pumpkinseed $+5 \%$ groundnut, $\quad \mathrm{SFF}_{3}=40 \% \mathrm{Barley}+15 \%$ Teff $+20 \% \mathrm{Bean}+15 \% \mathrm{Sesame}+10 \%$ groundnut, $\mathrm{SFF}_{4}=40 \%$ Barley $+15 \%$ Teff $+20 \%$ Bean $+15 \%$ PumpkinSeed $+10 \%$ groundnut and $\mathrm{SFF}_{5}=40 \%$ Barley $+15 \%$ Teff $+20 \%$ Bean $+10 \%$ sesame $+10 \%$ Pumpkin Seed + $5 \%$ groundnut; CV coefficient of variation

\section{Ranking and Selection}

Ranking was done to identify the optimal RTSSMF formulation based on the method as in previous study [23]. High content of protein, energy value, bioavailability of iron and calcium, were used as a criterion to rank and select the optimal RTSSMF formulation. The RTSSMF which has lowest score was chosen as the formulation most suitable nutritional benefits. As per table $6, \mathrm{SFF}_{1}$ had the lowest rank score, high nutritional value, and bioavailability of minerals. Therefore, treatment $\mathrm{SFF}_{1}$, formulation of Barley $=40 \%$; Teff $=15 \%$; Bean $=20 \%$; Sesame $=5 \%$; Pumpkin Seed $=15 \%$ and Groundnut $=5 \%$ had the most desirable nutritional benefits among the formulated five RTSSMF.

Table 6. Ranking of formulated supplementary maternal foods.

\begin{tabular}{llllll}
\hline Treatments & Protein & Energy & Phytate: Fe & Phytate: Ca & Total \\
\hline $\mathrm{SFF}_{1}$ & 1 & 3 & 2 & 7 \\
$\mathrm{SFF}_{2}$ & 3 & 1 & 3 & 2 & 3 \\
$\mathrm{SFF}_{3}$ & 3 & 2 & 1 & 2 & 2 \\
$\mathrm{SFF}_{4}$ & 1 & 4 & 3 & 1 \\
$\mathrm{SFF}_{5}$ & 2 & 1 & 4 & 3 \\
\hline
\end{tabular}

$\mathrm{SFF}_{1}=40 \%$ Barley $+15 \%$ Teff $+20 \%$ Bean $+5 \%$ Sesame $+15 \%$ PumpkinSeed $+5 \%$ groundnut,

$\mathrm{SFF}_{2}=40 \%$ Barley $+15 \%$ Teff $+20 \%$ Beans $+15 \%$ Sesame $+5 \%$ Pumpkinseed $+5 \%$ groundnut, $\quad \mathrm{SFF}_{3}=40 \% \mathrm{Barley}+15 \% \mathrm{Teff}+20 \% \mathrm{Bean}+15 \%$ sesam $+10 \%$ groundnut, $\mathrm{SFF}_{4}=40 \%$ Barley $+15 \%$ Teff $+20 \%$ Bean $+15 \%$ PumpkinSeed $+10 \%$ groundnut and $\mathrm{SFF}_{5}=40 \%$ Barley $+15 \%$ Teff $+20 \% \mathrm{Bean}+10 \%$ sesame $+10 \%$ Pumpkin Seed + $5 \%$ groundnut

\section{Conclusion and Recommendation}

The ready to serve supplementary maternal food formulations were compared for nutritional composition, antinutritional factor, bioavailability, and sensory evaluation. The various supplementary maternal drink formulations have shown satisfactory result in terms of bioavailability of minerals and providing protein and energy to supplement the required additional nutrients during pregnancy and lactation. Incorporating micronutrient rich seeds such as teff, pumpkin seeds and beans increased, the amount of mineral formulated foods. Dehusking and mild roasting also improved the nutritional value and organoleptic properties. Even though the formulations were low in calcium, its recommended to use milk instead of water to enrich the drink with calcium.
This finding showed that the supplementary maternal powdered drinks were acceptable and nutritious and could meet the required additional nutrient demand for pregnant and lactating mothers. The formulation of $\mathrm{SFF}_{1}$ which is Barley $=40 \%$; Teff $=15 \%$; Bean $=20 \%$; Sesame $=5 \%$; Pumpkin Seed $=15 \%$ and Groundnut $=5 \%$ RTSSMF had the most desirable nutritional value among the five formulated treatments. To meet the daily Dietary Reference Intake (DRI) it is recommended to drink $500 \mathrm{ml}$ of the supplementary drink per day in addition to the ordinary meals. Preparing and drinking the supplementary food using milk is recommended for better nutritional benefits.

\section{Acknowledgements}

The author is grateful to the financial support provided by 
Ethiopian Institute of Agricultural Research and to the staff of food science and nutrition research directorate, for their unlimited support. The author thanks Professor Shimelis Admasu for his individual guidance.

\section{References}

[1] Picciano, M. F. (2003). Pregnancy and lactation: physiological adjustments, nutritional requirements and the role of dietary supplements. The Journal of nutrition, 133 (6), 1997S-2002S.

[2] Black, R. E., Victora, C. G., Walker, S. P., Bhutta, Z. A., Christian, P., De Onis, M.,... \& Maternal and Child Nutrition Study Group. (2013). Maternal and child undernutrition and overweight in low-income and middle-income countries. The lancet, 382 (9890), 427-451.

[3] Mecacci, F., Biagioni, S., Ottanelli, S., \& Mello, G. (2015). Nutrition in pregnancy and lactation: how a healthy infant is born. Journal of Pediatric and Neonatal Individualized Medicine (JPNIM), 4 (2), e040236.

[4] Bain, L. E., Awah, P. K., Geraldine, N., Kindong, N. P., Siga, Y., Bernard, N., \& Tanjeko, A. T. (2013). Malnutrition in SubSaharan Africa: burden, causes and prospects. Pan African Medical Journal, 15 (1).

[5] Lee, S. E., Talegawkar, S. A., Merialdi, M., \& Caulfield, L. E. (2013). Dietary intakes of women during pregnancy in low-and middle-income countries. Public health nutrition, 16 (8), 1340-1353.

[6] Ethiopian Demographic and Health Survey. (2016). FDRE.

[7] Dewey K. G. (2016). Reducing stunting by improving maternal, infant and young child nutrition in regions such as South Asia: evidence, challenges and opportunities. Maternal Child Nutr.; 12: $27-38$.

[8] Kebebu, A., Whiting, S. J., Dahl, W. J., \& Henry, C. J. (2013). Formulation of a complementary food fortified with broad beans (Vicia faba) in southern Ethiopia. African Journal of Food, Agriculture, Nutrition and Development, 13 (3).

[9] Mitzner K, Scrimshaw N, Morgan R. (1984) Improving the nutritional status of children during the weaning period. A manual for policymakers, program planners, and fieldworkers.

[10] AOAC. (2005). Official Methods of Analysis. Association of Official Analytical Chemists, 18th ed. Washington, D.C.

[11] AOAC. (2000). International Official methods of analysis of AOAC International. AOAC International. 18th ed.
[12] Pearson, D. (1976). The chemical analysis of foods. Longman Group Ltd.

[13] Guyot, J. P., I. Rochette, and S. Treche. (2007). Effect of fermentation by amylolytic lactic acid bacteria, in process combinations, on characteristics of rice/soybean slurries: a new method for preparing high energy density complementary foods for young children. Food Chem. 100: 623-663.

[14] Latta M, Eskin M. A. (1980) simple and rapid colorimetric method for phytate determination. J Agric Food Chem.; 28: 1313-1315.

[15] Oduro I, Ellis WO, Sulemana A, Oti-Boateng P. (2007). Breakfast meal from breadfruit and soybean composite. 19: 181-276.

[16] Institute of Medicine. (2002) Panel on Macronutrients Report on dietary reference intakes for energy, carbohydrate, fiber, fat, fatty acids, cholesterol, protein, and amino acids. Washington, DC.

[17] World Health Organization, \& United Nations University. (2007). Protein and amino acid requirements in human nutrition (Vol. 935). World Health Organization.

[18] Institute of Medicine. (2005). Dietary Reference Intakes for energy, carbohydrate, fiber, fat, fatty acids, cholesterol, protein, and amino acids. Washington, D. C.: The National Academies Press.

[19] Institute of Medicine. (2001). Dietary Reference Intakes for vitamin A, vitamin K, arsenic, boron, chromium, copper, iodine, iron, manganese, molybdenum, nickel, silicon, vanadium, and zinc. Washington, D.C. The National Academies Press.

[20] Donangelo, C. M., \& King, J. C. (2012). Maternal zinc intakes and homeostatic adjustments during pregnancy and lactation. Nutrients, 4 (7), 782-798.

[21] FAO/WHO. Vitamin and Mineral Requirements in Human Nutrition. Geneva. (2004.) The World Health Organization and The Food and Agricultural Organization of the United Nations.

[22] Institute of Medicine (US) Standing Committee on the Scientific Evaluation of Dietary Reference Intakes. (1997). Dietary reference intakes. Dietary Reference Intakes for Calcium, Phosphorus, Magnesium, Vitamin D, and Fluoride.

[23] mIjarotimi, O. S., \& Keshinro, O. O. (2021). Formulation and nutritional quality of infant formula produced from germinated popcorn, Bambara groundnut and African locust bean flour. Journal of Microbiology, Biotechnology and Food Sciences, 2021, 1358-1388. 